\title{
Project of Monitory on the surveillance of the Pregnant Woman in Population of the General Hospital of Ecatepec JMR
}

\author{
Adriana Fernández Moral*1 and Martin Noé Rangel Calvillo ${ }^{2}$ \\ ${ }^{1}$ Graduate in Infirmary and Obstetrics, Specialist in infirmary Perinatal, Diplomada in Psicoprofilaxis perinatal, Teacher in administration with orientation \\ in human approach, Mexico
}

${ }^{2}$ Researcher in national system, Ascribed to the general Hospital of Ecatepec, Mexico

Received: May 20, 2018; Published: June 21, 2018

*Corresponding author: Adriana Fernández Moral, Graduate in Infirmary and Obstetrics, Specialist in infirmary Perinatal, Diplomada in Psicoprofilaxis perinatal, Teacher in administration with orientation in human approach, Mexico, Email: drrangelcalvillo@gmail.com

\section{Introduction}

In time prehispánicos to the pregnancy surrendered him all type of cults for considering him holy, thus, the féminas in gestation enjoyed of privileges and special cares, between which stood out frequent visits and consultancy of the partera, the one who besides provided them councils so that the future baby will develop properly and did them see that the childbirth was a satisfactory experience and gozosa that did not have to live with suffering, but this is not everything, since also they practised ritual so that it kept in optimum conditions and offered banquets in his honour. When it arrived the moment of the alumbramiento, the partera received to the boy with tender sentences to the time that cut him the umbilical cord, later, expected the expulsion of the placenta, proceeded to bathe to the baby and invoked the protection of the gods. Some basic appearances of the present philosophy have restarted it the instructors in psicoprofilaxis, discipline that provides to the future mum knowledge on gestation, childbirth and form to handle the pain and anxiety during the alumbramiento; it can resort to this method from the fourth month of pregnancy (12.16.17).

a) Problem: In spite of the monitory made in our unit with the purpose to influence in the causes of maternal death and perinatal, can observe that they continue presenting cases of pregnant women, that when they attend to be attended of childbirth, do not have sufficient information to strengthen the presence of a normal or physiological childbirth; Thus we will give us to the task to investigate his origin and the degree of knowledge that have about the program of security of the pregnant woman, which tentativamente applies in first level of attention, monitored the number of queries by patient.

\section{Aims Especificos}

Know the percentage of our population that knows the plan of security during the pregnancy.

\section{Method}

Monitory of the surveillance of the pregnant woman of the zone of Ecatepec during the period comprised of October of 2016 to January of 2017. We will apply survey to quantify the percentage of pregnant women that gather or not the requirements for security for childbirth, as well as those that received qualification. We will analyse resulted calculating Relative Risk and Reason of Momios. Also it calculated Factor exhibition according to table of $4 \times 4$ (Table 1).

\section{Results}

After the application of the questionnaire attain to poll to 578 pregnant women and present the results in percentages considering each one of the questions:

a) It asks 1 they are knowledgeable of the course preparation of for childbirth? $15 \%$ of the respondents (87 participants) answered afirmativamente

b) It asks 2 I Take course of preparation for childbirth? (grafica 1), 83 women answered afirmativamente that is to say $14 \%$ and $85 \% 495$ women) answered negatively (grafica 2)

c) It asks 3 they taught Him data of alarm before and after his childbirth? 173 women that is to say $30 \%$ if it received it and 405, 70\% compound of 405 participants answered of negative way. (Grafica 3)

d) It asks 4 Know how much hard the work of childbirth? 80 women that involves $14 \%$ answered that yes and 498 that is to say $86 \%$ answered No (grafica 4 )

e) It asks 5 it knows you what time last the contractions and number of them in 10 minutes? Only $20 \%$ answers afirmativamente that is to say 118 patients and 460 that translates $80 \%$ the desconoce.(grafica 5) 
f) It asks 6 Know what do when it presents a data of alarm? 423 women answered that yes and is $73 \%$ and the negative answer obtained in 27\% 155 (grafic 6)

g) It asks 7 Know what do in case of some complication? 274 women do not know and is $47 \% .53 \%$ that is to say 304 women if they know what do (grafic 7)

h) It asks 8In which time arrives to the hospital? Average injure 424 patients 1 hour 125 patients until 2 hrs 28 and more than 2 hrs 1 patient (grafic 8)

i) It asks 9Those that consult prenatales tube during his pregnancy in centre of Health? It did not have them 54 women. An alone time 41 women, 2 times 78 participants 3 times 54 women and more than 3times 351(grafica 9)

j) It asks10 It knows plan of security in his pregnancy? If they know it 23\% (131 patients) do not know it 447 women that translates in $77 \%$ of the respondents (grafica 10)

k) It asks 11 how many times attended to service of urgencies before giving to light?

$>$ Of 3 times 14\% (84 women), 3 times 13\% (75women) .2 times $26 \%$ (to 48 patients) an alone time 271 women (47\%) (Grafica 11)

Statistical analysis

$\mathrm{OR}=\mathrm{To} / \mathrm{b} / \mathrm{b} / \mathrm{d}=0.9469435$

$\mathrm{RR}=\mathrm{To}+\mathrm{c} / \mathrm{b}=1 \quad$ relative Risk $=1$

Factor Exposed $=$ exhibition/ Patients: FEp $=3.37$

The pregnant patients that attend without knowledge on plan of security in the pregnancy in the present study present in 1 , with a FAITH of 3.37 and an OR 0.94694. In the majority of the questions made find a big opportunity of improvement for the education of the population in the culture of the education prenatal.

\section{Comments}

Urgent that the authorities commissioned of the follow-up of maternal health and perinatal enteren of the present analysis so that taking advantage of the opportunities of improvement found in this first monitory, turn instructions to the managers of attention of woman and pregnant woman in first level for in base to qualification in the population reduce the risk of the population to present complications during the work of childbirth and for the recently bo.

\section{Antecedents}

Between the Aztecs the woman encinta was taken care jealously, offered him ceremonies, bathrooms with aromatic grasses, as well as sessions of relaxation and exercise, what allowed him live comfortably the gestation and give to light without suffering, this process, in the actuality, is being rescued through the preparation for the childbirth psicoprofiláctic. In time prehispánicos to the pregnancy surrendered him all type of cults for considering him holy, thus, the féminas in gestation enjoyed of privileges and special cares, between which stood out frequent visits and consultancy of the partera, the one who besides provided them councils so that the future baby will develop properly and did them see that the childbirth was a satisfactory experience and gozosa that did not have to live with suffering, but this is not everything, since also they practised ritual so that it kept in optimum conditions and offered banquets in his honour.

When it arrived the moment of the alumbramiento, the partera received to the boy with tender sentences to the time that cut him the umbilical cord, later, expected the expulsion of the placenta, proceeded to bathe to the baby and invoked the protection of the gods. Some basic appearances of the present philosophy have restarted it the instructors in psicoprofilaxis, discipline that provides to the future mum knowledge on gestation, childbirth and form to handle the pain and anxiety during the alumbramiento; it can resort to this method from the fourth month of pregnancy. (12.16.17). By the previous, is important to take in account that to win said annoyances is necessary to do to a side the fear, what can achieve when the féminas are conscious of what occurs inside his organism during the nine months of pregnancy, if they know the form in that it develops the childbirth and if besides they practise physical exercises, respiratory and of relaxation.

There are women that bring a son to the world if suffer, whereas others suffer ailments during the birth, why presents this contrast? The degree of pain associates with the emotional state, as it has showed that when the mother is nervous, tired and anxious feels greater annoyance in the moment in that they present the contractions. It is common that the future mums suffer during the childbirth due to the fact that they feel fear, since they always have heard to say that give to light is a painful proof; in consequence, presents muscular rigidity, condition that favours the painful feeling. On the other hand, there are families where the environment is sober and considers to the alumbramiento like a natural and satisfactory event, what allows giving to light in shape calm and relaxed $(1,8,6)$, The birth is a normal and natural process, but even the "pregnancies of low risk" can suffer complications. Sometimes it is necessary an intervention to obtain the best result. So that the following recommendations are viable, is necessary a deep transformation of the sanitary services beside modifications in the attitudes of the personnel and the redistribution of the human and material resources.

\section{General Recommendations}

a) The ministries of health have to establish specific norms on the appropriate technology for the childbirth in the public and private sectors.

b) The countries have to effect conjoint investigations to evaluate the technologies of attention to the childbirth.

c) All the community has to be informed of the distinct methods of attention to the childbirth, so that each woman can choose the type of childbirth that prefer.

d) Has to encourage to the mothers and to his families to practise the autocuidado in the period perinatal, and to recognise when need help and of which type to improve the conditions of the pregnancy, childbirth and puerperium. 
e) The groups of mutual help between mothers offer a valuable social support and an only opportunity to share information on the childbirth.

f) The sanitary team has to boost coherent attitudes to guarantee the continuity in the control of the childbirth, and the team perinatal has to share a philosophy of common work, so that the changes of personnel do not hamper the continuity in the attention.

g) The informal systems of attention perinatal (like the parteras traditional) have to coexistir with the official system, and have to keep a spirit of collaboration in profit of the mother. Such relations can be very effective when they establish in parallel.

h) The training of the professionals has to transmit the new knowledge's on the social appearances, cultural, anthropological and ethical of the childbirth.

Childbirth psicoprofilàctico, birth without pain-Health and Medicines, www.saludymedicinas.com.mx > Centre of Pregnancy

a) The team perinatal has to be motivated jointly to strengthen the relations between the mother, his son and the family. The work of the team can see affected by interdisciplinary conflicts, that have to tackle systematically.

b) The training of the sanitary professionals has to include technicians of communication to promote a respectful exchange of information between the members of the sanitary team and the pregnant and his families.

c) It has to promote the training of parteras or comadronas professional. The attention during the pregnancy, childbirth and normal puerperium has to be competition of this profession.

d) The evaluation of the technology has to involve to all those that use said technology, epidemiólogos, sociologists, sanitary authorities and the women in which it uses the technology.

e) The information on the practical obstétricas in the different hospitals, like the tax of cesáreas, has to be near at hand of the public.

f) It has to investigate to regional level, national and international on the structure and composition of the team of attention to the childbirth, with the aim to attain the maximum access to the suitable primary attention and the greater possible proportion of normal childbirths, improving the health perinatal, according to criteria of cost-effectiveness and the needs and wishes of the community.

\section{Specific Recommendations}

a) For the welfare of the new mother, a member chosen of his family has to have free access during the childbirth and all the period postnatal. Besides, the sanitary team also has to loan emotional support. b) The women that give to light in an institution have to conserve his right to decide on clothes (his and the one of the baby), food, destination of the placenta and other culturally important practices.

c) The recently born healthy has to remain with the mother whenever it was possible.

d) The observation of the recently born healthy does not justify the separation of his mother.

e) It has to recommend the lactancia immediate, even before the mother abandon the room of childbirths.

f) Some of the countries with a lower mortality perinatal in the world have less than a $10 \%$ of cesáreas. It cannot justify that any country have more than a 10-15\%.

g) There are not proofs that after a cesárea previous were necessary a new cesárea.

h) After a cesárea has to recommend usually a vaginal childbirth, whenever it was possible a surgical intervention of emergency.

i) The ligadura of the trompas of Falopio is not an indication of cesárea. They exist methods simpler and insurances of sterilisation tubárica.

j) It does not exist evidence that the routine fetal monitoring have a positive effect on the result of the pregnancy. The fetal monitoring electronics only has to effect in cases carefully selected by his high risk of mortality perinatal, and in the childbirths induced. They require more studies on the selection of the women that could benefit of the fetal monitoring. Between so much, the national services of health would have to abstain to purchase new teams.

k) It recommends control the fetal cardiac frequency by auscultation during the first phase of the childbirth, and with greater frequency during the expulsivo.

l) It is not indicated rasurar the fluff pubiano or administer an enema before the childbirth.

m) It does not recommend plant to the pregnant in dorsal position of litotomía during the dilatation and the expulsivo. It has to recommend walk during the dilatation, and each woman has to decide freely which position adopt during the expulsivo.

n) It has to protect the perineo whenever it was possible. It is not justified the systematic use of the episiotomía.

o) The induction of the childbirth has to reserve for specific medical indications. Any region would have to have more than a $10 \%$ of inductions.

p) During the expulsivo has to avoid the routine administration of analgesics or anaesthetic (except that need specifically to correct or warn some complication).

q) It is not justified the artificial precocious break of membranes like procedure of routine. 
r) They require more studies to value which is the minimum of special clothes that have to carry those who attend to the childbirth or to the recently born.

\section{Application of the Recommendations}

a) The previous recommendations recognise differences between distinct countries and regions, his application has to adapt to each circumstance.

b) The governments have to determine which departments have to coordinate the evaluation of the appropriate technology for the childbirth.

c) The universities, scientific societies and groups of investigation have to participate in the evaluation of the technology.

d) The norms of finance have to discourage the use indiscriminado of technologies.

e) It has to boost an attention obstétrica criticism with the technological attention to the childbirth and respectful with the emotional appearances, psychological and social of the childbirth.

f) The governmental organisms, universities, scientific societies, and other groups interested would have to be able to control the excessive practice and injustificada of the cesárea, investigating and giving to know his harmful effects on the mother and the son.

g) The WHO and the OPS have to promote a network of groups of evaluation to help to the countries to adopt new technologies developed by countries more advanced. This network will convert to his time in a centre for the diffusion of the information.

h) The results of the evaluation of the technology have to be widely spread to change the behaviour of the professionals and the attitudes of the public in general.

i) Only after an accurate evaluation owe the governments consider the development of norms to allow the use of new technologies for the childbirth.

j) They have to promote national and regional meetings on the childbirth, that include to sanitary professionals, sanitary authorities, users, groups of women and media.

k) The WHO and the OPS have to designate a year during which the attention centres in the promotion of a better birth.

\section{The Human Rights in the Childbirth and Birth}

It exists an international legal frame very wide that identifies fully the rights related with the reproductive life:

a) Right to the personal dignity: Art. 1, Universal Statement of the Human rights.

b) Art. 11, American Convention on Human rights.

c) Right to the life, to the freedom, to the security and integrity of the people: Art. 1 American Statement of the Rights and
Duties of the Man; Art. 4, 5 and 7, American Convention on Human rights; Art. 6 and 9, International Pact of Civil Rights and Politicians; Art. 6, Convention on the Rights of the Boy.

d) Right to not being subjected to tortures neither to penalties or cruel deals, inhuman or degrading: Art. 5, American Convention on Human rights; Art. 7 International Pact of Civil Rights and Politicians; Art. 37, Convention on the Rights of the Boy.

e) Right to the health: Art. 12, International Pact of Economic Rights, Social and Cultural; Art. 24, Convention on the Rights of the Boy, the right to the health has to understand like a right to the enjoy of all a range of eases, goods, services and necessary conditions to reach the highest possible level of health and with the best scientific knowledge available (9.12.15).

Recommendations of the WHO on the childbirth and birth,www.crececontigo.gob.cl/wp-content/.../Recommendations-WHO-on-the-childbirth. Pdf, Statement of Fortress. World Health Organisation. Appropriate technology for the childbirth.

i. Right to the equality in the attention of the health and that there is not discrimination by reasons of social class, age, race or etnia: International Pact on Rights, Economic, Social and Cultural.

ii. Against the Woman (Belém do Pará), adopted by the National Assembly of the American States, defines the violence against the woman like "all action or behaviour based in the gender that cause death, damage or suffering, physicist, sexual or psychological, so much in the public field as in the private".

iii. These treaties force to the States to establish legal procedures, just and effective of access to the justice $(3,2,4,5,12)$

\section{Population in Study}

The Sanitary Jurisdiction Ecatepec locates in the Northwest of the State of Mexico, has two municipalities of responsibility, the one of Ecatepec of Morelos (with 155.5 square kilometres) and the one of Coacalco of Berriozábal (with 35.5 square kilometres), with a territorial extension of 191 square kilometres and represents $0.94 \%$ of the surface of the State of Mexico. Geographically it finds located south of the meridional plateau of the country, situated in a minimum length of $98^{\circ} 58^{\prime} 30^{\prime \prime}$ and a maximum length of $99^{\circ} 07^{\prime} 44^{\prime \prime}$ in regard to the meridian of Greenwich, likewise, in a minimum latitude of $19^{\circ} 29^{\prime} 02^{\prime \prime}$ and a maximum latitude of $19^{\circ} 39^{\prime} 30^{\prime \prime}$ in regard to the Ecuador his altitude is situated between 2,251 and 2,268 metres above sea level.

\section{Limits}

North with the municipality of Tultitlán, Tultepec, Jaltenco and Tecámac, south with the Federal District and the municipalities of Texcoco and Nezahualcóyotl, west with the Federal District and the municipalities of Tultitlán and Tlalnepantla, to the East with the municipalities of Atenco, Acolan and Jaltenco, The total population of this Jurisdiction considered for the year 2014 is of 2,085,078 inhabitants, being the Sanitary Jurisdiction with greater number of 
inhabitants so much in the national field as in the state; the population represents roughly the $13.7 \%$ of the total of mexiquenses. The population density is of $10,916.6$ inhabitants by square kilometre.

\section{Question}

They are receiving, the pregnant women sufficient information, By part the centres of health, to improve cares preconcepciones of health, in the mother and he drinks?

\section{Problem}

In spite of the monitory made in our unit with the purpose to influence in the causes of maternal death and perinatal, can observe that they continue presenting cases of pregnant women, that when they attend to be attended of childbirth, do not have sufficient information to strengthen the presence of a normal or physiological childbirth.; Thus we will give us to the task to investigate his origin and the degree of knowledge that have about the program of security of the pregnant woman, which tentativamente applies in first level of attention, monitored the number of queries by patient respondent with the purpose, to define the degree or percentage of ignorance of the culture of surveillance perinatal, especially in relation to the application of the cares prenatales.

\section{Delimitation of the Problem}

At present in our unit follow attending, big quantity of Pregnant women of high complexity .Or that well complicate during the attention of the childbirth by fault of cares during the pregnancy. In front of this wish to measure some factors of great importance, that are hitting even from the attention pre hospitable.

\section{Type of Study}

We will make a transversal study, prospectivo observational by means of application of questionnaires to the patients that access to go in to the project in the room of touch surgery of our unit. The study is original, effected with own and low resources strict consentimiento writing by participants.

\section{Universe of work}

Pregnant women that attend to the service of touch-surgery to be attended, during the period of October to January of the 2017.se calculated a sample by means of program of Stata of 300 particip before

\section{Criteria of inclusion:}

a) Patients that attend to desembarazarse to the unit of touch of the hospital GE.

b) Pregnant that authorises to participate and fill questionnaire.

c) Pregnant that have attended in Centres of health

d) Pregnant in work of childbirth that are in conditions to answer the questionnaire

\section{Criteria of Exclusion:}

Women in work of childbirth with alterations of the state of consciousness. a) Women that deny to participate in the scrutiny

b) Women that have not had contact during the pregnancy with centres of health. Women that do not finish to $100 \%$ the questionnaire

\section{Ethical Implications}

They do not violate the agreements of Helsinki to the not putting in risk neither the integrity, health, welfare neither identity of the participants.5. Conflict of Interests

The researchers do not have conflict of interest, the present study only, has interest of type medico scientist and do not receive any stimulus of some type by companies or laboratory.

\section{General Aim}

Measure the number of patients that are knowledgeable of the course of plan of security of the pregnant woman

How many women took the course?

Those that the data of alarm, length of the work of childbirth

$\%$ Of women that Knows how much last the contractions

\section{Aims Especificos}

Know the percentage of our population that knows the plan of security during the pregnancy, Propiciar And incidir in the personnel of health, empathy, cordialidad and professionalism from the start, of his pregnancy, of a woman, until his transfer to the Hospitable Unit where will be attended his childbirth and his recently born, in the different units asistenciales of first level (Centres of Health) Offer to the pregnant woman, information about the process of pregnancy, mechanism of work of childbirth, puerperium, lactancia maternal and cares of recently born.

\section{Method}

Monitory of the surveillance of the pregnant woman of the zone of Ecatepec during the period comprised of October of 2016 to January of 2017. We will apply survey to quantify the percentage of pregnant women that gather or not the requirements for security for childbirth, as well as those that received qualification. We will analyse resulted calculating Relative Risk and Reason of Momios. Also it calculated Factor exhibition according to table of 4 x 4 (Table 1).

Table 1: Conceptual diagram of risk, where appreciates the need to find opportunities of improvement.

\begin{tabular}{|c|c|c|}
\hline Factor of risk & $\begin{array}{c}\text { Cases with R/N } \\
\text { complicated }\end{array}$ & \# Of cases \\
\hline Patients & To & $\mathrm{b}$ \\
CASES & Patients UCIN & $\begin{array}{c}\text { Pregnant attended } \\
\text { during the period }\end{array}$ \\
\hline Healthy & $\mathrm{c}$ & $\mathrm{d}$ \\
CONTROLS & Pregnant respondents & $\begin{array}{c}\text { Population no } \\
\text { respondent }\end{array}$ \\
\hline
\end{tabular}

Where to $=\#$ of $\mathrm{R} / \mathrm{N}$ that were born in bad conditions

Where $b=$ \# of women attended in Unit of touch Surgery 
Where $c=$ \# of pregnant respondents in period of time with factors of exhibition

Where $\mathrm{d}=$ \# of $\mathrm{R} / \mathrm{N}$ that were born in period without problems

\section{Results}

After the application of the questionnaire attain to poll to 578 pregnant women and present the results in percentages considering each one of the questions:

a) It asks 1.- They are knowledgeable of the course of $15 \%$ of the respondents(87 participants) answered afirmativamente

b) It asks 2.- I take course of preparation for childbirth? (grafica 1)83 women answered afirmativamente that is to say $14 \%$ and $85 \% 495$ women) answered negatively (grafica 2)

c) It asks 3.- They taught him data of alarm before and after his childbirth? 173 women that is to say $30 \%$ if it received it and $405,70 \%$ compound of 405 participants answered of negative way.(grafica 3)

d) It asks 4.- Know how much hard the work of childbirth? 80 women that involves $14 \%$ answered that yes and 498 that is to say $86 \%$ answered No (grafica 4 )

e) It asks 5.- It knows you what time last the contractions and number of them in 10 minutes? Only 20\% answers afirmativamente that is to say 118 patients and 460 that translates $80 \%$ the desconoce.(grafica 5)

f) It asks 6.- Know what do when it presents a data of alarm? 423 women answered that yes and is $73 \%$ and the negative answer obtained in 27\% 155 (grafica 6)

g) It asks 7.- Know what do in case of some complication? 274 women do not know and is $47 \% .53 \%$ that is to say 304 women if they know what do (grafica 7)

h) It asks 8.-In which time arrives to the hospital? Average injure 424 patients 1 hour 125 patients until 2 hrs 28 and more than 2 hrs 1 patient (grafica 8)

i) It asks 9.- Those that consult prenatales tube during his pregnancy in centre of Health? It did not have them 54 women. An alone time 41 women, 2 times 78 participants .3 times 54 women and more than 3times 351(grafica 9)

j) It asks10.- It knows plan of security in his pregnancy? If they know it 23\% (131 patients) do not know it 447 women that translates in $77 \%$ of the respondents (grafica 10)

k) It asks 11.- How many times attended to service of urgencies before giving to light? > Of 3 times 14\% ( 84 women), 3 times 13\% (75women) .2 times $26 \%$ (to 48 patients) an alone time 271 women (47\%) (Grafica 11)

\section{Conclusion}

Applying Conceptual Diagram of risk (suggested from 1949 to business level) could detect $85 \%$ of probabilities of opportunity for improvement in our field as it observes in diagram: In the present applies conceptual diagram of risk applied to a medical problem, more than business and as we observe can give us light on the problematic concerning the fault of qualification of the population and the way of how hits the risk in the health of the vulnerable population (Table 2).

Table 2: The pregnant patients that attend without knowledge on plan of security in the pregnancy in the present study present in 1, with a FAITH of 3.37 and an OR 0.94694.

\begin{tabular}{|c|c|c|}
\hline Factor of risk & $\begin{array}{c}\text { Cases with R/N compli- } \\
\text { cated }\end{array}$ & \# Of cases \\
\hline Patients & To & $\mathrm{b}$ \\
CASES & Patients UCIN $=740$ & $\begin{array}{c}\text { Pregnant attended } \\
\text { during the period= } \\
2220\end{array}$ \\
\hline Healthy & $\mathrm{c}$ & $\mathrm{d}$ \\
CONTROLS & $\begin{array}{c}\text { Pregnant respondents } \\
=528\end{array}$ & $\begin{array}{c}\text { Population no re- } \\
\text { spondent }\end{array}$ \\
& & $=1642$ \\
\hline
\end{tabular}

$\mathrm{OR}=\mathrm{To} / \mathrm{b} / \mathrm{b} / \mathrm{d}=0.9469435$

$\mathrm{RR}=\mathrm{To}+\mathrm{c} / \mathrm{b}=1$, Relative Risk $=1$

Factor Exposed $=$ exhibition/ Patients: FEp $=3.37$

A) Opportunities of improvement according to results of survey

According to the result of the surveys and of direct way can observe that it has $85 \%$ of opportunities of improvement to work the diffusion of the course between the communities. In the case of the application of course the $85 \%$ of the population represents opportunity of improvement to apply the course especially in first level of attention. And in order of responsibilities will be of the responsible authorities of the follow-ups to institutional level that improve in these rubros if we want to spread cares perinatales between the populations. The majority of the women that complicate during the work of childbirth present delay to present to hospitable level and can be that one of the causes is that we find in the population studied that $70 \%$ do not know the data of alarm by what could be origin of said delay.

The $86 \%$ of the respondents do not know even how much hard in work of childbirth and this ignorance can very influence in states of anxiety that generate complications during the development of childbirth.

$80 \%$ of the respondents represent opportunities of improvement to qualify to the population in characteristics and length of contractions. It calls us the attention that in the question 6 solo $27 \%$ of the group in study do not know data of alarm which deband be analysed future work to review the causes or origin of the one who is are receiving this information and the way in that they assimilate it to be able to learn of this and implement projects to strengthen this road of communication. $47 \%$ of the group are not bodyroadsteads of complications that is the question 7 and offers also a big opportunity of improvement for together with the others rubros direct efforts to improve the system of qualification to the 
population even strengthening it with some didactic technician the knowledge in the pregnant woman.

In the time of arrive to the hospital when seeming does not have problems however a patient refers to have taken more than $2 \mathrm{hrs}$ to arrive, by what has to re evaluate this factor and watch the roads and the means of existent transport in our area and try improve it for the profit of the binomial. One of the fundamental bases of the fetal welfare and of the woman that is tested hits of direct way in the neonatal and maternal mortality, is the plan of security installed especially in first level of attention and that it was created to ensure the welfare of the binomial and with this reduce material and human losses, and in the present study found that at least $77 \%$ of the population studied does not know said plan of security, obviously of this plan surface the rest of the questions that already have been desglosadas and seems us that the own system of health has to explain now with this $77 \%$ of opportunities to improve it if we want to modify of positive way the neonatal and maternal mortality in our region. The last question about the number of times in that it attended to urgencies $47 \%$ attended only once and calls us the attention by the high percentage of complications with which explain. However it does lacking to investigate in another moment if of these women that attend only once elevates the number of complications or of which way hits in the final result of the attention of the binomial.

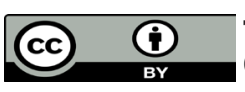

This work is licensed under Creative Commons Attribution 4.0 License

Submission Link: https://biomedres.us/submit-manuscript.php

\section{B) Comments}

Urgent that the authorities commissioned of the follow-up of maternal health and perinatal enteren of the present analysis so that taking advantage of the opportunities of improvement found in this first monitory, turn instructions to the managers of attention of woman and pregnant woman in first level for in base to qualification on program of security, in the population reduzca the risk to present complicacionis during the work of childbirth for the recently born and the mother.

\section{Recommendations}

It watches closely the systems of security for the pregnant mothers, specifically in this analysis the plan of security for the same that by forcing has to of appliesrse in first level of attention. We observe opportunities of improvement in each one of the questions during the survey immediately and without preamble can observe to where have to direct my actions of improvement and surveillance of the area in question. Of course implement a system of aseguramiento of the action so that to future measure the impact in the health of the population and the impact in level of risk found in the present. The attendants of the system of security in the pregnant woman can incidir with the managers of application in first level so that they cover the opportunities in the population of immediate way.

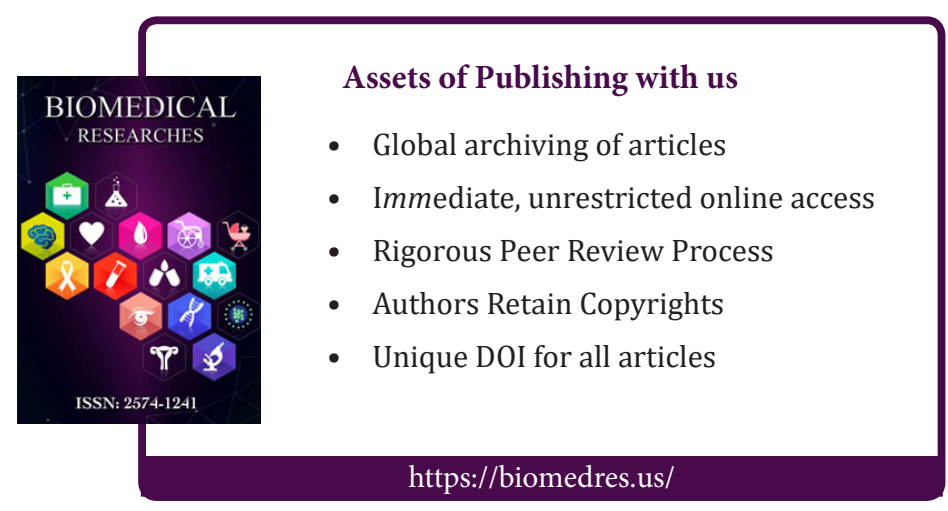

